EFFECTIVENESS BULLETIN

\title{
Effects of interventions for the treatment of nocturnal enuresis in children
}

\section{M A Glazener, R E Peto, J H C Evans}

Qual Saf Health Care 2003;12:390-394

The effectiveness of interventions for the treatment of nocturnal enuresis in children published in a recent issue of Effective Health Care is reviewed.

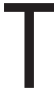
his article is based on a recent issue of Effective Health Care which focused on the effects of interventions for the treatment of nonorganic nocturnal enuresis in children.

Nocturnal enuresis (bedwetting) is the involuntary loss of urine at night, in the absence of physical disease, at an age when a child could reasonably be expected to be dry (by consensus, at a developmental age of 5 years ). ${ }^{23}$ Although bedwetting has a high rate of spontaneous remission, it may bring social and emotional stigma, stress and inconvenience to both the person with enuresis and their families. ${ }^{4}$ Children who wet the bed may experience parental disapproval, sibling teasing, and repeated treatment failure which may lower self-esteem. ${ }^{5}$

Nocturnal enuresis affects many families. Estimating the prevalence of nocturnal enuresis is difficult, however, because there is variation in methods of diagnosis and in definitions. ${ }^{67}$ In the UK the most recent estimates suggest that the prevalence of frequent bedwetting (more than once a week) is higher in boys and shows a steady decline with age. ${ }^{8-10}$ Around one in six children aged 5 years regularly wet the bed compared with around one in 20 children aged 11 years. ${ }^{8-10}$

Various interventions are used to treat nocturnal enuresis (box 1). These include enuresis alarms, drugs such as desmopressin, simple behavioural methods such as star charts, and more complex behavioural methods including dry bed training. Other less common interventions include psychotherapy, surgery, fluid deprivation, and complementary therapies.

\section{NATURE OF THE EVIDENCE}

Based on a series of systematic reviews, this paper focuses on the research evidence for the effects of interventions for the treatment of non-organic nocturnal enuresis in children. The systematic reviews were carried out by the authors and are available from the Cochrane Library. " The Cochrane reviews are all based on a previous systematic review originally published in 1997 as part of the CRD Report series. ${ }^{12}$

Relevant trials were identified from the Group's specialised register of controlled trials which is described in The Cochrane Library. ${ }^{11}$ The register contains trials identified from MEDLINE, CINAHL, the Cochrane Central Register of Controlled Trials (CENTRAL), and hand searching of journals and relevant conference proceedings. In addition, the cited references from the included trials were searched. Full details of review methods are available from the Cochrane Library. ${ }^{11}$

Although over 100 randomised controlled trials (RCTs) have been included in the Cochrane reviews, there are few direct comparisons between different types of intervention. The difficulty in comparing interventions is exacerbated by the lack of uniformity in outcome measures and the failure of some studies adequately to assess baseline levels of bed wetting. Many of the included RCTs have methodological problems such as small sample sizes and high rates of attrition (dropouts) leading to low statistical power

Box 1 Interventions used to treat nocturnal enuresis

\section{Behavioural interventions}

- Lifting: involves taking the child to the toilet during the night usually before the time that bedwetting is expected, without necessarily waking the child.

- Waking: involves waking the child to allow him/her to get up and urinate.

- Reward systems (e.g. star charts): the child might receive a star for every dry night, and a reward after a preset number of stars have been earned.

- Retention control training: attempting to increase the functional bladder capacity by delaying urination for extended periods of time during the day.

- Stop-start training: teaching children to interrupt their stream of urine in order to strengthen their pelvic floor muscles

- Dry bed training can include enuresis alarms, waking routines, positive practice, cleanliness training, bladder training, and rewards.

\section{Enuresis alarms}

- Enuresis alarms wake the child in the night a the onset of wetting. When a child begins to urinate a sensor (either a bed pad or one worn inside pyjamas) is moistened and the alarm is triggered.

- Overlearning: may be initiated after successful alarm treatment (e.g. achievement of 14 consecutive dry nights). Extra drinks are given at bedtime to cause additional stress to the detrusor muscles in the bladder. Alarm treatment is then continued until 14 consecutive dry nights are once again achieved.

\section{Pharmacological interventions}

- Drugs used include desmopressin and, less commonly, tricyclic drugs such as imipramine, amitriptyline, and nortriptyline. 
Comparison: Alarm v control

Outcome: Number cured (achieving 14 consecutive dry nights)

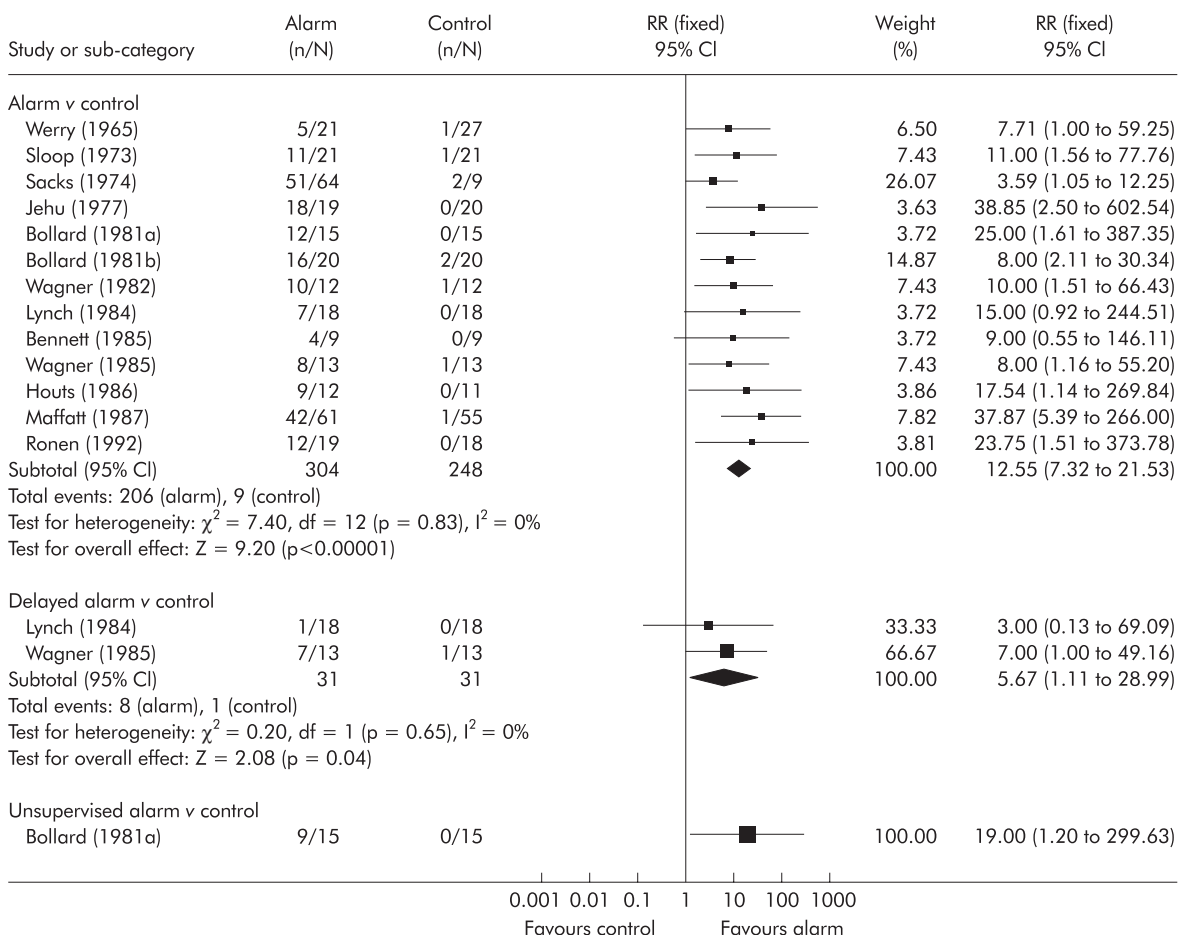

Figure 1 Comparison of alarm treatment with control interventions on the number of children with nocturnal enuresis achieving 14 consecutive dry nights.

and potential bias. In addition, many are poorly reported. For example, many trial authors give insufficient detail about the method of randomisation or adequately report follow up data.

A number of the included RCTs have recruited children by advertising in the media or from enuresis clinics. Participating families may have been especially motivated to tackle the bed wetting. In addition, strict inclusion/exclusion criteria were imposed in many of the trials. Consequently, the children involved are not necessarily representative of the wider population of those who wet the bed, either in the community or in institutions.

\section{EFFECTIVENESS}

\section{Behavioural interventions other than alarms}

Simple behavioural interventions are widely used as standard first line treatment. Twelve RCTs were included in a Cochrane review assessing the effects of simple behavioural interventions. ${ }^{13}$ None were of good methodological quality. The review found that star charts, with or without lifting or waking, were associated with significantly fewer wet nights and lower failure rates while on treatment and higher long term success after treatment. However, each finding was based on a single small trial. Of the two trials addressing retention control training, one was too small to provide meaningful information and the other had a very high dropout rate (80\%). Another small trial showed that there might be some benefits associated with cognitive therapy compared with star charts, but these findings will need to be confirmed in other larger trials.

A feature of the included RCTs was high dropout or non-adherence rates. Families reported that waking the child at night was disruptive and often too stressful, raising the possibility that some of these simple behavioural interventions may not be suitable for all.

A number of RCTs have been conducted to assess the effectiveness of complex behavioural treatment programmes such as dry bed training. Although originally reviewed in the 1997 systematic review undertaken by $\mathrm{CRD},{ }^{12}$ an update is nearing completion and will be available as a Cochrane review later this year. ${ }^{14}$

\section{Alarms}

Fifty three RCTs were included in a Cochrane review assessing the effects of alarm interventions for nocturnal enuresis. ${ }^{15}$ The methodological quality of many of the RCTs was poor. Many were too small to be likely to find statistically significant differences, even where some difference may exist, and often only one small trial compared alarms with another method. In these circumstances no conclusions can be drawn.

The main findings of the review were that alarm treatment was more effective during treatment than control interventions (fig 1) and in terms of success rates after treatment was completed (fig 2). About half the children remained dry after using alarms compared with almost none of those who received no treatment or waiting list control (RR 12.67, 95\% CI 4.06 to 39.52 ).

Most of the alarms evaluated were of the type that woke the child immediately by means of a bell or buzzer. Insufficient evidence was found to draw conclusions about the relative effectiveness of different types of alarm, although some types may be more effective. There was some limited evidence that an immediate alarm was better than a delayed alarm, and that one which woke the child rather than the parents had better results. Children were reported to prefer a body-worn alarm to a bed pad and alarm.

The Cochrane review included eight RCTs which compared alarms with a variety of simple behavioural interventions including star charts, rewards, wakening, lifting and stopstart training (pelvic floor muscle training). ${ }^{15}$ Most of the trials comparing behavioural interventions with alarms tended to favour alarms. Alarms were found to be better than stop-start training in terms of wet nights per week, both during and after treatment, in one small trial. There were no statistically 
Comparison: Alarm v control

Outcome: Numbers remaining cured (achieving 14 dry nights and not relapsing)

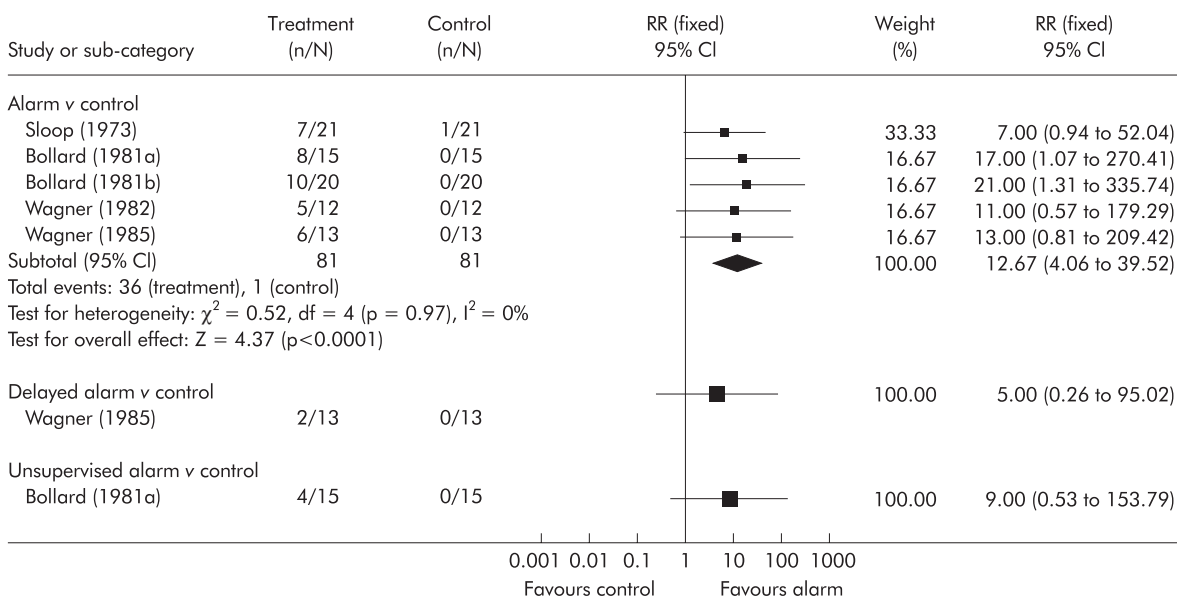

Figure 2 Comparison of alarm treatment with control interventions on the number of children with nocturnal enuresis who achieved 14 consecutive dry nights and did not relapse.

significant differences between alarms and methods such as lifting, wakening, or rewards in four other small trials, although all trials favoured alarms in respect of a reduction in mean wet nights. There was not enough evidence to conclude whether supplementing alarm treatment with behavioural interventions improved the effectiveness of the alarm.

The Cochrane review included 18 RCTs that involved comparisons between alarms and drugs, either alone or in combination. ${ }^{15}$ Limited evidence suggested that alarms were better than drug treatment. Although desmopressin appeared to have a more immediate effect, alarms were more effective by the end of a course of treatment (RR $0.71,95 \%$ CI 0.50 to 0.99 ) and after treatment stopped (RR $0.27,95 \%$ CI 0.11 to $0.69)$. Alarms were also found to be better than tricyclic antidepressants both during (RR $0.73,95 \%$ CI 0.61 to 0.88 ) and after treatment stopped (RR $0.58,95 \%$ CI 0.36 to 0.94 ). Insufficient reliable evidence was found to support the practice of supplementing alarm treatment with drug interventions.

Most alarms wake the child immediately using a bell or buzzer but then require nightwear, and perhaps bedding, to be changed. High dropout rates in some of the trials included in the Cochrane review suggest that there were problems with adherence, often reflecting the unacceptability of the intervention. Potential difficulties such as the time needed to attain success and the disruption to the family need to be discussed before embarking on alarm treatment. In two trials nonadherence or dropout was attributed to the equipment being too difficult or complicated to use. A small number of RCTs included in the review involved alarms which delivered electric shocks to the children's skin. The use of these alarms was clearly unacceptable to parents and children, and they sometimes caused side effects such as skin burns and ulceration.

\section{Drugs}

Three Cochrane reviews have assessed the effects of drug therapy on nocturnal enuresis in children. ${ }^{16-18}$ One of these reviews covers the less commonly used drugs and is currently being updated and will be available later this year. ${ }^{18}$

Forty one RCTs were included in a Cochrane review assessing the effects of desmopressin. ${ }^{16}$ The review found that there was clear evidence that desmopressin (in a variety of doses and forms) was better at reducing the number of wet nights per week during treatment than placebo (fig 3). However, after treatment stopped the limited evidence available suggested that this improvement was not sustained.

Another Cochrane review of 54 RCTs found that treatment with tricyclic or related drugs (imipramine, amitriptyline, viloxazine, clomipramine and desipramine but not mianserin) was associated with a reduction of about one wet night per week while on treatment. ${ }^{17}$ For example, imipramine was better at reducing the number of wet nights per week during treatment than placebo (weighted mean difference $-1.19,95 \%$ CI -1.56 to -0.82 ). However, although about a fifth of the children became dry while on treatment (86/400 achieved 14 dry nights on imipramine compared with $22 / 413$ on placebo), this effect was not sustained after treatment stopped (6/192 on imipramine compared with $7 / 209$ on placebo).

Insufficient reliable evidence was found comparing desmopressin with tricyclics or other related drugs. Likewise, there was a lack of reliable evidence comparing desmopressin or tricyclics with simple and complex behavioural interventions.

The British National Formulary (BNF) currently suggests that drug therapy is not usually appropriate for children under 7 years of age and should be reserved for children in whom alternative measures have failed. ${ }^{19}$ Fluid overload is potentially the most serious complication with desmopressin. It is associated with overdrinking at bedtime and its symptoms include headache, nausea, hyponatraemia, cerebral oedema, and convulsions. Tricyclic antidepressants have significant adverse effects including cardiotoxic and hepatotoxic effects in overdose. Minor side effects related to their anticholinergic actions include postural hypotension, dry mouth, constipation, perspiration, tachycardia, nausea, lethargy and insomnia. The BNF recommends that the possible side effects of the various drugs should be considered and that any prescription should not be continued for longer than 3 months without stopping for a full reassessment. ${ }^{19}$

\section{IMPLICATIONS}

Much of the available research on the effects of interventions used to treat nocturnal enuresis in children is of poor quality and there are few direct comparisons between different types of intervention.

Simple behavioural interventions are widely used as standard first line treatment but they can require a high level of parental involvement. There is currently little evidence to show that these interventions work.

The use of an alarm intervention has been shown to reduce night time bed wetting in most children both during treatment and after treatment stops. Overlearning (giving children extra fluids at bedtime after successfully becoming dry using an alarm) may reduce the relapse rate. Before embarking on alarm treatment, families need to be made 
Comparison: Desmopressin $v$ placebo

Outcome: Number of wet nights per week during treatment

\begin{tabular}{|c|c|c|c|c|c|c|c|}
\hline Study or sub-category & $\mathrm{N}$ & $\begin{array}{c}\text { Desmopressin } \\
\text { Mean (SD) }\end{array}$ & $N$ & $\begin{array}{l}\text { Placebo } \\
\text { Mean (SD) }\end{array}$ & $\begin{array}{c}\text { WMD (fixed) } \\
95 \% \mathrm{Cl}\end{array}$ & $\begin{array}{c}\text { Weight } \\
(\%)\end{array}$ & $\begin{array}{c}\text { WMD (fixed) } \\
95 \% \mathrm{Cl}\end{array}$ \\
\hline \multicolumn{8}{|l|}{$10 \mu \mathrm{g} \vee$ placebo } \\
\hline Aladjem (1982) & 15 & $1.52(2.15)$ & 17 & $4.40(1.94)$ & $\rightarrow$ & 62.07 & $-2.88(-4.31$ to -1.4 \\
\hline Kjoller (1984) & 13 & $2.49(2.52)$ & 12 & $3.84(2.13)$ & $\rightarrow$ & 37.93 & $-1.35(-3.17$ to 0.47$)$ \\
\hline Subtotal $(95 \% \mathrm{Cl})$ & 28 & & 29 & & - & 100.00 & $-2.30(-3.42$ to -1.1 \\
\hline
\end{tabular}

Test for heterogeneity: $\chi^{2}=1.68, \mathrm{df}=1(p=0.20), \mathrm{I}^{2}=40.4 \%$

Test for overall effect: $Z=4.01(p<0.0001)$

\begin{tabular}{|c|c|c|c|c|c|c|c|}
\hline \multicolumn{8}{|l|}{$20 \mu \mathrm{g} \vee$ placebo } \\
\hline Folwell (1997) \# & 31 & $3.24(2.51)$ & 31 & $4.86(1.95)$ & $\rightarrow$ & 4.29 & $-1.62(-2.74$ to -0.50$)$ \\
\hline Tuvemo (1978) \# & 18 & $1.60(1.82)$ & 18 & $3.97(2.20)$ & $\rightarrow$ & 3.09 & $-2.37(-3.69$ to -1.05$)$ \\
\hline Segni (1982) & 20 & $2.20(1.34)$ & 20 & $4.20(1.79)$ & $\leftarrow$ & 5.59 & $-2.00(-2.98$ to -1.02$)$ \\
\hline Post (1983 B) \# & 20 & $4.90(1.92)$ & 20 & $5.80(1.14)$ & $\rightarrow$ & 5.60 & $-0.90(-1.88$ to 0.08$)$ \\
\hline Kioller (1984) & 12 & $2.45(1.84)$ & 12 & $3.84(2.13)$ & $\rightarrow-$ & 2.12 & $-1.39(-2.98$ to -0.20$)$ \\
\hline Terho (1984) \# & 54 & $2.16(2.00)$ & 54 & $4.02(1.83)$ & - & 10.27 & $-1.86(-2.58$ to -1.14$)$ \\
\hline Janknegt (1990) \# & 22 & $3.40(2.50)$ & 22 & $5.30(1.80)$ & $\rightarrow$ & 3.24 & $-1.90(-3.19$ to -0.61$)$ \\
\hline Rushton (1995) & 49 & $3.96(2.37)$ & 47 & $4.90(1.64)$ & - & 8.14 & $-0.94(-1.75$ to -0.13$)$ \\
\hline Skoog (1997) & 33 & $4.00(1.15)$ & 36 & $5.00(1.20)$ & - & 17.46 & $-1.00(-1.55$ to -0.45$)$ \\
\hline Sener (1998) & 31 & $1.10(1.39)$ & 25 & $5.10(2.00)$ & $\rightarrow$ & 6.29 & $-4.00(-4.92$ to -3.08$)$ \\
\hline Schulmen (2001a) & 44 & $4.00(1.33)$ & 47 & $4.50(1.37)$ & $=$ & 17.45 & $-0.50(-1.05$ to 0.05$)$ \\
\hline Schulmen (2001b) & 109 & $4.00(1.57)$ & 38 & $5.00(1.54)$ & - & 16.45 & $-1.00(-1.57$ to -0.43$)$ \\
\hline \multicolumn{8}{|l|}{$40 \mu \mathrm{g} \vee$ placebo } \\
\hline Post (1983 A) \# & 52 & $3.90(2.34)$ & 52 & $5.00(1.91)$ & - & 17.27 & $-1.10(-1.92$ to -0.28$)$ \\
\hline Janknegt (1990) \# & 22 & $3.80(2.20)$ & 22 & $5.30(1.80)$ & $=$ & 8.25 & $-1.50(-2.69$ to -0.31$)$ \\
\hline Martin (1993) & 22 & $2.16(2.25)$ & 22 & $3.68(2.25)$ & $\rightarrow-$ & 6.58 & $-1.52(-2.85$ to -0.19$)$ \\
\hline Skoog (1997) & 33 & $3.50(1.44)$ & 36 & $5.00(1.20)$ & - & 29.47 & $-1.50(-2.13$ to -0.87$)$ \\
\hline Yap (1998) \# & 34 & $2.50(2.70)$ & 34 & $4.50(2.10)$ & $\rightarrow$ & 8.81 & $-2.00(-3.15$ to -0.85 \\
\hline Schulmen (2001a) & 48 & $3.50(1.73)$ & 47 & $4.50(1.37)$ & - & 29.62 & $-1.00(-1.63$ to -0.37$)$ \\
\hline Subtotal $(95 \% \mathrm{Cl})$ & 211 & & 213 & & $\bullet$ & 100.00 & $-1.33(-1.67$ to -0.99$)$ \\
\hline \multicolumn{8}{|c|}{ Test for heterogeneity: $\chi^{2}=3.11, d f=5(p=0.68), 1^{2}=0 \%$} \\
\hline \multicolumn{8}{|c|}{ Test for overall effect: $Z=7.63(p<0.00001)$} \\
\hline \multicolumn{8}{|l|}{$60 \mu \mathrm{g} v$ placebo } \\
\hline Skoog (1997) & 33 & $3.50(1.15)$ & 36 & $5.00(1.20)$ & 를 & 56.09 & $-1.50(-2.05$ to -0.95$)$ \\
\hline Schulmen (2001a) & 48 & $3.00(1.73)$ & 47 & $4.50(1.37)$ & $=$ & 43.91 & $-1.50(-2.13$ to -0.87$)$ \\
\hline Subtotal $(95 \% \mathrm{Cl})$ & 81 & & 83 & & $\bullet$ & 100.00 & $-1.50(-1.91$ to -1.08$)$ \\
\hline \multicolumn{8}{|c|}{ Test for heterogeneity: $\chi^{2}=0.00, d f=1(p=1.00), 1^{2}=0 \%$} \\
\hline \multicolumn{8}{|c|}{ Test for overall effect: $Z=7.08(p<0.00001)$} \\
\hline \multicolumn{8}{|c|}{ Combined dose $v$ placebo } \\
\hline Birkasova (1978) \# & 22 & $2.10(2.25)$ & 22 & $5.50(2.20)$ & + & 100.00 & $-3.40(-4.71$ to -2.09$)$ \\
\hline \multicolumn{8}{|l|}{ Dose titration $v$ placebo } \\
\hline Rushton (1995) & 49 & $3.77(2.25)$ & 47 & $4.90(1.82)$ & $=$ & 32.13 & $-1.13(-2.01$ to -0.25$)$ \\
\hline Schulmen (2001b) & 99 & $3.20(1.69)$ & 36 & $5.00(1.54)$ & $=$ & 67.87 & $-1.80(-2.40$ to -1.20$)$ \\
\hline Subtotal $(95 \% \mathrm{Cl})$ & 148 & & 83 & & • & 100.00 & $-1.58(-2.08$ to -1.09$)$ \\
\hline \multirow{2}{*}{\multicolumn{8}{|c|}{$\begin{array}{l}\text { Test for heterogeneity: } \chi^{2}=1.52, \mathrm{df}=1(p=0.22), \mathrm{I}^{2}=34.3 \% \\
\text { Test for overall effect: } Z=6.25(p<0.00001)\end{array}$}} \\
\hline & & & & & & & \\
\hline & & & & -10 & 5 & 5 & \\
\hline
\end{tabular}

Figure 3 Comparison of desmopressin versus placebo on number of wet nights per week during treatment in children with nocturnal enuresis.

aware of both the time and the high level of parental involvement necessary to attain success.

Drug treatment such as desmopressin reduces the number of wet nights per week compared with placebo, but only for as long as the drug is used. However, drugs can be used as a way to reduce the frequency of wetting for a specific purpose such as nights away from home-for example, for holidays or when staying with friends. Patients and their families need to be warned about possible side effects of some of the drugs.

Future research must be of higher methodological quality, involve comparisons between those interventions used most commonly in practice, be undertaken in appropriate settings, and include follow up periods of longer duration.

\section{Authors' affiliations}

C M A Glazener, Health Services Research Unit, University of Aberdeen, UK

R E Peto, Centre for Reviews and Dissemination, University of York, UK J H C Evans, Nottingham City Hospital NHS Trust, Nottingham, UK

\section{REFERENCES}

1 Centre for Reviews and Dissemination. Nocturnal enuresis in children. Effective Health Care 2003;8(2).
2 World Health Organization. Nonorganic enuresis. The ICD-10 classification of mental and behavioural disorders: clinical descriptions and diagnostic guidelines. Geneva: World Health Organization, 1992.

3 American Psychiatric Association. Functional enuresis. Diagnostic and statistical manual of mental disorders. 3rd ed. Washington: American Psychiatric Association, 1980.

4 Fitzwater D, Macknin ML. Risk/benefit ratio in enuresis therapy. Clin Pediatr 1992:308-10.

5 Warzak WJ. Psychosocial implications of nocturnal enuresis. Clin Pediatr 1992:38-40.

6 de Jonge GA. Epidemiology of enuresis: a survey of the literature. In: Kolvin I, et al, eds. Bladder control and enuresis. London: William Heinemann Medical Books, 1973.

7 Krantz I, Jylkas E, Ahlberg BM, et al. On the epidemiology of nocturnal enuresis: a critical review of methods used in descriptive epidemiological studies on nocturnal enuresis. Scand J Urol Nephrol 1994:75-82.

8 Blackwell C. A guide to enuresis: a guide to treatment of enuresis for professionals. Bristol: ERIC, 1989.

9 Rona R, Li L, Chinn S. Determinants of nocturnal enuresis in England and Scotland in the '90s. Dev Med Child Neurol 1997;39:667-81.

10 Swithinbank L, Brookes S, Shepherd APA. The natural history of urinary symptoms during adolescence. BrJ Urol 1998:81:90-3.

11 Update Software. The Cochrane Library. Oxford: Update Software, 2003.

12 NHS Centre for Reviews and Dissemination. A systematic review of the effectiveness of interventions for managing childhood nocturnal enuresis. CRD Report 11. York: University of York, 1997.

13 Glazener CMA, Evans JH. Simple behavioural interventions for nocturnal enuresis in children. The Cochrane Library. Issue 2. Oxford: Update Software, 2003 
14 Glazener CMA, Evans JH. Complex behavioural interventions for nocturnal enuresis in children. The Cochrane Library. Issue 2. Oxford: Update Software, 2004 (in press).

15 Glazener CMA, Evans JH, Peto R. Alarm interventions for nocturnal enuresis in children (Cochrane Review). The Cochrane Library. Issue 2. Oxford: Update Software, 2003.

16 Glazener CMA, Evans JHC. Desmopressin for nocturnal enuresis in children (Cochrane Review). The Cochrane Library. Issue 2. Oxford: Update Software, 2003.
17 Glazener CMA, Evans JH, Peto R. Tricyclic and related drugs for nocturnal enuresis in children (Cochrane Review). The Cochrane Library. Issue 2. Oxford: Update Software, 2003.

18 Glazener CMA, Evans JH. Drugs for nocturnal enuresis in children (other than desmopressin and tricyclics) (Cochrane Review). The Cochrane Library. Issue 4. Oxford: Update Software, 2003.

19 British Medical Association, Royal Pharmaceutical Society of Great Britain. British National Formulary. London: British Medical Association, Royal Pharmaceutical Society of Great Britain, 2003.

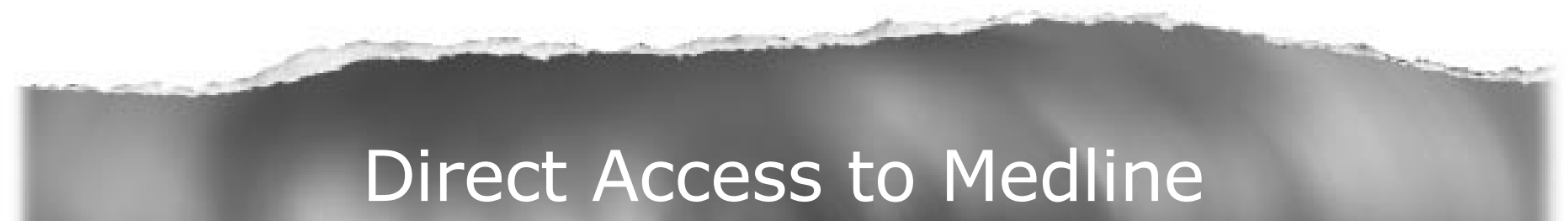

\section{Medline}

Link to Medline from the homepage and get straight into the National Library of Medicine's premier bibliographic database. Medline allows you to search across 9 million records of bibliographic citations and authors abstracts from approximately 3,900 current biomedical journals.

\section{www.qshc.com}

